\title{
Mercury Contamination of Aquatic Ecosystems
}

\section{U.S. Department of the Interior-U.S. Geological Survey}

\section{Introduction}

Mercury has been well known as an environmental pollutant for several decades. As early as the 1950's it was established that emissions of mercury to the environment could have serious effects on human health. These early studies demonstrated that fish and other wildlife from various ecosystems commonly attain mercury levels of toxicological concern when directly affected by mercury-containing emissions from human-related activities. Human health concerns arise when fish and wildlife from these ecosystems are consumed by humans.

During the past decade, a new trend has emerged with regard to mercury pollution. Investigations initiated in the late 1980's in the northern-tier states of the U.S., Canada, and Nordic countries found that fish, mainly from nutrient-poor lakes and often in very remote areas, commonly have high levels of mercury. More recent fish sampling surveys in other regions of the U.S. have shown widespread mercury contamination in streams, wet-lands, reservoirs, and lakes. To date,
33 states have issued fish consumption advisories because of mercury contamination (fig. 1). These continental to global scale occurrences of mercury contamination cannot be linked to individual emissions of mercury, but instead are due to widespread air pollution. When scientists measure mercury levels in air and surface water, however, the observed levels are extraordinarily low (fig. 2). In fact, scientists have to take extreme precautions to avoid direct contact with water samples or sample containers, to avert sample contamination (fig. 3). Herein lies an apparent discrepancy: Why do fish from some remote areas have elevated mercury concentrations, when contamination levels in the environment are so low?

\section{How does mercury become a toxicological problem?}

Like many environmental contaminants, mercury undergoes bioaccumulation. Bioaccumulation is the process by which organisms (including humans) can take up contaminants more rapidly

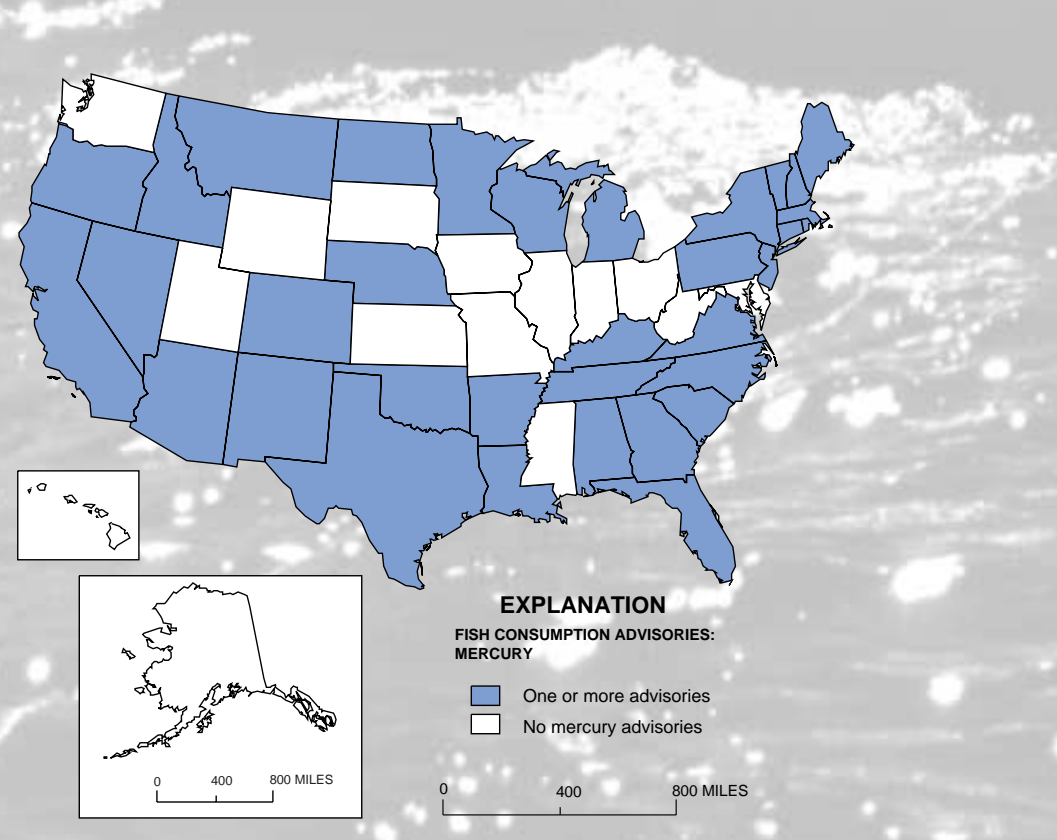

Figure 1. States with at least one fish consumption advisory for mercury. Source: USEPA Fish Consumption Data Base

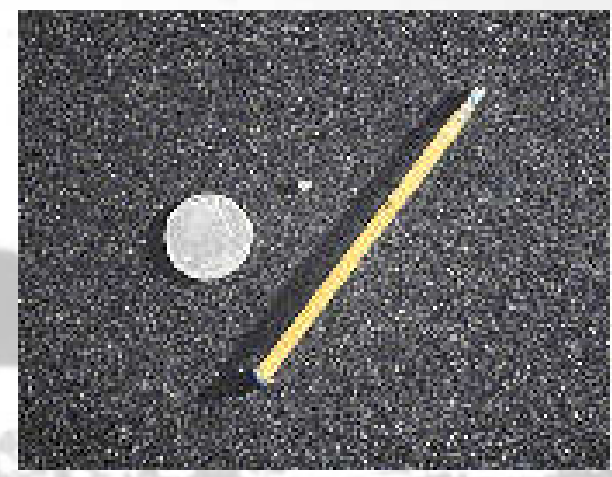

Figure 2. The droplet of mercury shown in this slide is about 1 gram; the same amount that is in a standard mercury thermometer and the total amount that is deposited annually on a lake in northern Wisconsin with a surface area of 27 acres.

than their bodies can eliminate them, thus the amount of mercury in their body accumulates over time. If for a period of time an organism does not ingest mercury, its body burden of mercury will decline. If, however, an organism continually ingests mercury, its body burden can reach toxic levels. The rate of increase or decline in body burden is specific to each organism. For humans, about half the body burden of mercury can be eliminated in 70 days if no mercury is ingested during that time. Biomagnification is the incremental increase in concentration of a contaminant at each level of a food chain (fig. 4). This phenomenon occurs because the food source for organisms higher on the food chain is progressively more concentrated in mercury and other contaminants, thus magnifying bioaccumulation rates at the top of the food chain. The bioaccumulation effect is generally compounded the longer an organism lives, so that larger predatory game fish will likely have the highest mercury levels. Adding to this problem is the fact that mercury concentrates in the muscle tissue of fish. So, unlike organic contaminants (for example PCBs and dioxins) which concentrate in the skin and fat, mercury cannot be filleted or cooked out of consumable game fish. 


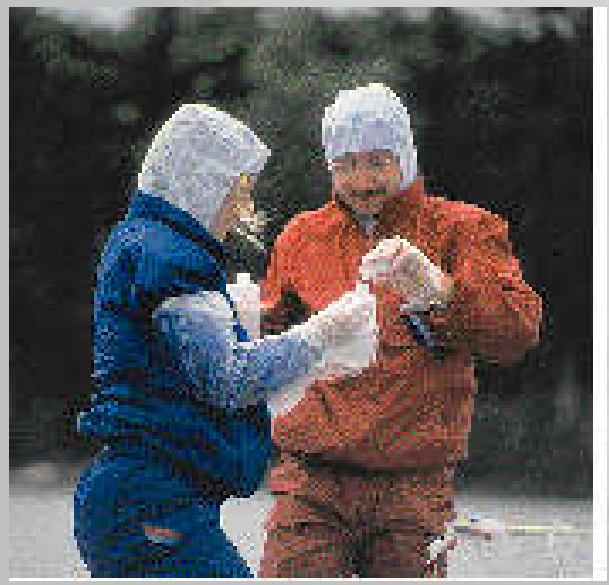

Figure 3. Because there is actually very little mercury in most natural waters, scientists have to use extreme measures when sampling for mercury to avoid sample contamination from their hands and clothing. This entails the use of lint-free suits, plastic gloves, hoods, and stringently cleaned sampling equipment.

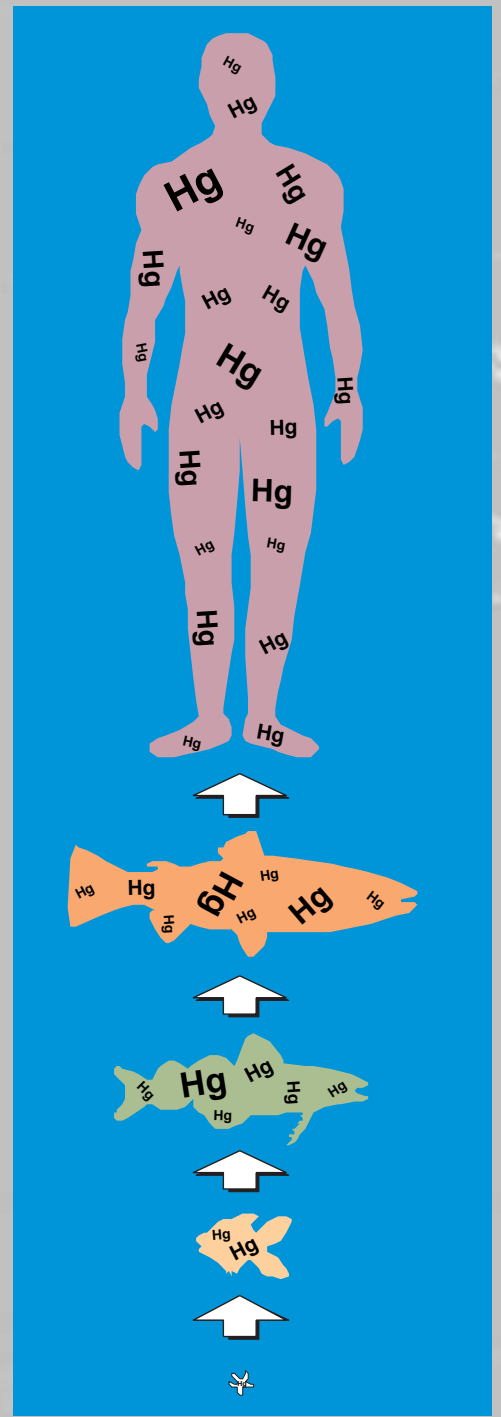

Figure 4. Mercury $(\mathrm{Hg})$ biomagnifies from the bottom to the top of the food chain. Even at very low input rates to aquatic ecosystems that are remote from point sources, biomagnification effects can result in mercury levels of toxicological concern.

\section{What are the human health effects of mercury toxicity?}

Humans generally uptake mercury in two ways: (1) as methylmercury $\left(\mathrm{CH}_{3} \mathrm{Hg}^{+}\right)$from fish consumption, or (2) by breathing vaporous mercury $\left(\mathrm{Hg}^{0}\right)$ emitted from various sources such as metallic mercury, dental amalgams, and ambient air. Our bodies are much more adapted for reducing the potential toxicity effects from vaporous mercury, so health effects from this source are relatively rare. Methylmercury, on the other hand, affects the central nervous system, and in severe cases irreversibly damages areas of the brain (fig. 5). The most well documented cases of severe methylmercury poisoning are from Minamata Bay, Japan in 1956 (industrial release of methyl-mercury) and in Iraq in 1971 (wheat treated with a methylmercury fungicide). In each case, hundreds of people died, and thousands were affected, many with permanent damage. In milder cases of mercury poisoning, adults complain of reductions in motor skills and dulled senses of touch, taste, and sight. These milder effects are generally reversible if exposure to mercury is halted. Unborn children are at greatest risk from low-level exposure to methylmercury. Recent research suggests that prenatal effects occur at intake levels 5-

10 times lower than that of adults. If these results are confirmed, a substantial fraction of unborn children would be at risk.

\section{Mercury Cycling in the Environment}

Mercury can take a myriad of pathways through the environment. Figure 6 shows a schematic drawing of mercury cycling in an aquatic ecosystem. With the exception of isolated cases of known point sources, the ultimate source of mercury to most aquatic ecosystems is deposition from the atmosphere, primarily associated with rainfall. As depicted in this figure, atmospheric deposition contains the three principal forms of mercury, although the majority is as inorganic mercury $\left(\mathrm{Hg}^{2+}\right.$, ionic mercury). Once in surface water, mercury enters a complex cycle in which one form can be converted to another. It can be brought to the sediments by particle

\section{MERCURY HEALTH EFFECTS}

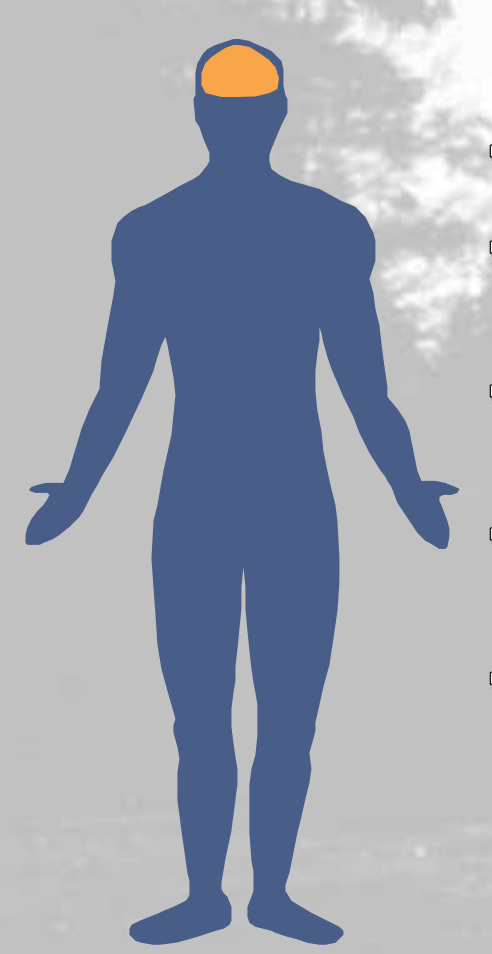

Deteriorates nervous system

- Impairs hearing, speech, vision and gait

- Causes involuntary muscle movements

- Corrodes skin and mucous membranes

Causes chewing and swallowing to become difficult

Figure 5. All forms of mercury are toxic to humans, but methylmercury is especially of concern because our bodies have a less well developed defense mechanism against this toxin. Effects on the nervous system are the most prevalent in humans. 
settling and then later released by diffusion or resuspension. It can enter the food chain, or it can be released back to the atmosphere by volatilization. The concentration of dissolved organic carbon (DOC) and $\mathrm{pH}$ have a strong effect on the ultimate fate of mercury in an ecosystem. Studies have shown that for the same species of fish taken from the same region, increasing the acidity of the water (decreasing $\mathrm{pH}$ ) and/or the DOC content generally results in higher body burdens in fish. Many scientists currently think that higher acidity and DOC levels enhance the mobility of mercury in the environment, thus making it more likely to enter the food chain. Many of the details of the aquatic mercury cycle are still unknown, however, and remain areas of active research.

\section{How does mercury enter the food chain?}

The exact mechanism(s) by which mercury enters the food chain remain largely unknown, and probably vary among ecosystems. We do know, however, that cer tain bacteria play an important early role. Studies have shown that bacteria that process sulfate $\left(\mathrm{SO}_{4}{ }^{=}\right)$in the environment take up mercury in its inorganic form, and through metabolic processes convert it to methylmercury. The conversion of inorganic mercury to methylmercury is important for two reasons: (1) methylmercury is much more toxic than inorganic mercury, and (2) organisms require considerably longer to eliminate methylmercury. At this point, the methylmercury-containing bacteria may be consumed by the next higher level in the food chain, or the bacteria may release the methylmercury to the water where it can quickly adsorb to plankton, which are also consumed by the next level in the food chain.

\section{Where does atmospheric mercury come from?}

There are many sources of mercury to the environment, both natural and man related. Natural sources include volcanoes, natural mercury deposits, and volatilization from the ocean. The primary human-related sources include: coal combustion, chlorine alkali processing, waste incineration, and metal processing. Best estimates to date suggest that human activities have about doubled or tripled the amount of mercury in the atmosphere, and the atmospheric burden is increasing by about 1.5 percent per year.

\section{Has there always been mercury contamination, or is this a recent problem?}

This is a difficult question to answer, in part because of a lack of adequately preserved fish specimens of preindustrial age to compare against contemporary samples. However, several lines of evidence from recent studies on Wisconsin lakes suggest that increased emissions to the atmosphere, and subsequent higher deposition rates to lakes, likely translate into higher mercury levels in fish. Although the total amount of mercury delivered to one of these lakes annually is very small (fig. 2), it is strongly absorbed by organic material floating in the water such as plankton or bacteria. These micro-organ-

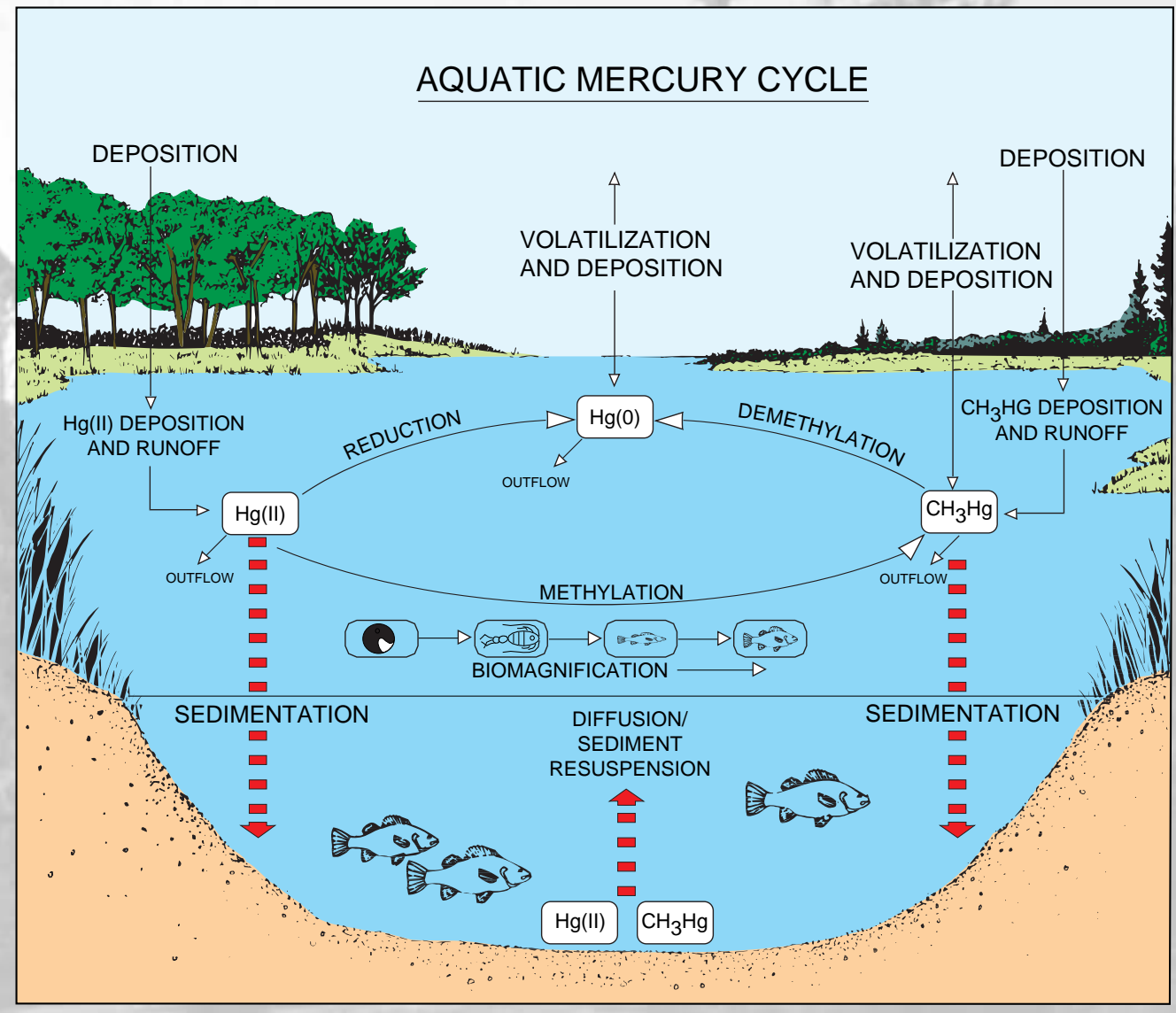

Figure 6. Mercury cycling pathways in aquatic environments are very complex. The various forms of mercury can be converted from one to the next; most important is the conversion to methylmercury $\left(\mathrm{CH}_{3} \mathrm{Hg}^{+}\right)$, the most toxic form. Ultimately, mercury ends up in the sediments, fish and wildlife, or evades back to the atmosphere by volatilization. Reprinted with permission from Mercury Pollution: Integration and Synthesis. Copyright Lewis Publishers, an imprint of CRC Press. 
plankton or bacteria. These microorganisms are consumed by organisms higher in the food chain, or after dying, settle to the bottom of the lake and are incorporated into bottom sediments. Studies of sediment cores show that younger sediments deposited since industrialization have mercury concentrations that are about 3-5 times that of historical sediments. Thus, the fact that these sediments are primarily composed of dead microorganisms that were once the bottom of the food chain would suggest that modern levels of mercury in the food chain are elevated over preindustrial times.

\section{If human-related emissions could be eliminated or reduced, how long would it take for ecosystems to recover?}

The only way to attempt to answer this question is to incorporate all the best information currently available on how mercury behaves in the environment into a computer model. Such a model was constructed as part of the research effort on northern Wisconsin lakes. Modeled scenarios predict that if emissions could be reduced by 5 percent, it would take 8 years before any change in fish concentrations would be observed, and the decrease would be small.

\section{The Role of the USGS in Mercury Studies}

As a national agency with a mission to describe the nation's water resources, the USGS is uniquely positioned to provide a

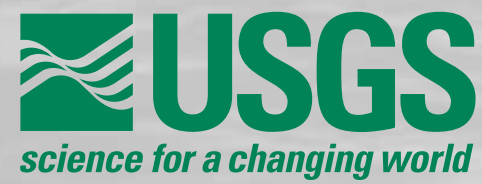

For more information contact:

\section{District Chief}

U.S. Geological Survey

Water Resources Division

6417 Normandy Lane

Madison, WI 53719 leadership role in aquatic mercury investigations. The USGS was a prominent participant in studies conducted in northern Wisconsin, which largely form the basis of current knowledge about mercury in aquatic ecosystems. With offices in every state, staffed with scientists trained in the collection of water samples, the USGS can conduct studies on mercury contamination throughout the country. The ongoing National Water-Quality Assessment (NAWQA) program provides additional infrastructure and expertise to gain a national perspective on mercury contamination. A recently established mercury research laboratory in Madison, Wisconsin gives USGS scientists the necessary analytical capability to conduct state-of-the-art contamination studies. Thus, the USGS is well situated to advance the understanding of mercury cycling in aquatic ecosystems and to assist resource management agencies in developing strategies for reducing the effects of mercury contamination.

D.P. Krabbenhoft and D.A. Rickert

\section{Suggested Reading}

Mercury as a Global Pollutant (D.B. Porcella, J.W. Huckabee, and B. Wheatley editors), Water, Air and Soil Pollution, 80 (1-4), 1995.

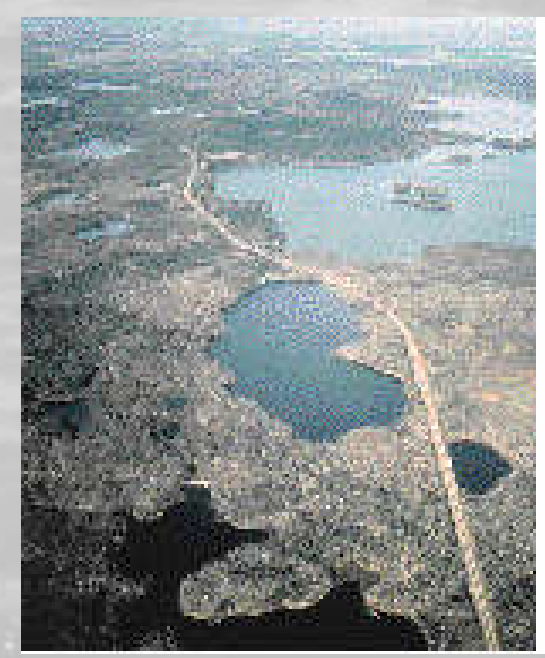

THE U.S. GEOLOGICAL SURVEY HAS PARTICIPATED IN MERCURY CYCLING STUDIES IN NORTHERN WISCONSIN LAKES.

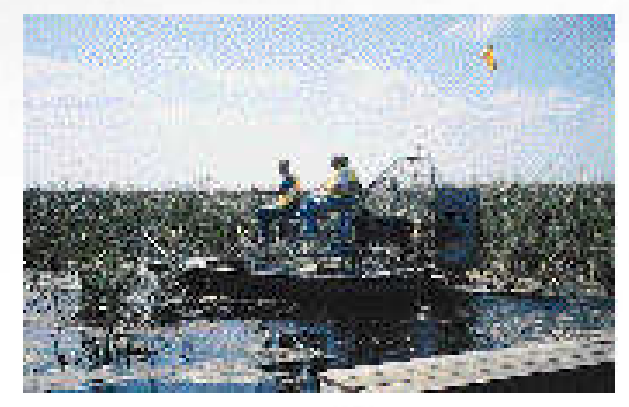

CURRENTLY, THE U.S. GEOLOGICAL SURVEY IS CONDUCTING MERCURY CYCLING STUDIES IN THE FLORIDA EVERGLADES.

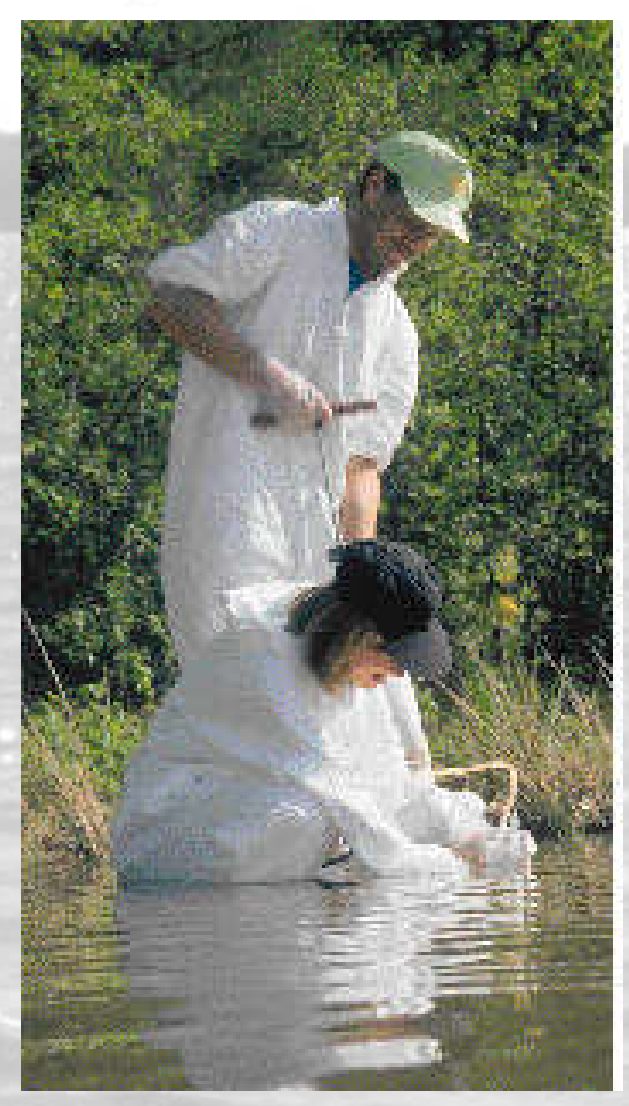

CLEAN SAMPLING TECHNIQUES CAN BE ADAPTED FOR USE IN ALMOST ANY ENVIRONMENT, INCLUDING WETLANDS, LAKES, AND STREAMS.

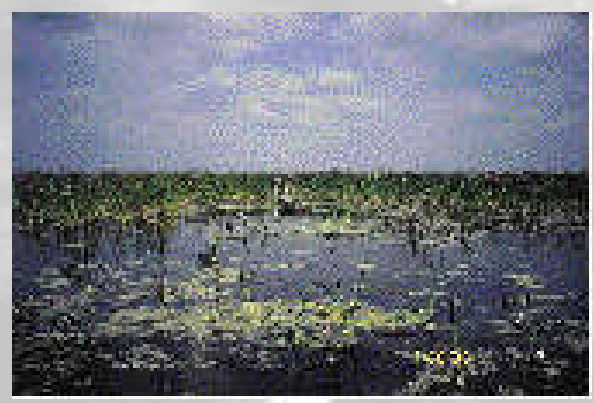

CURRENTLY, THE U.S. GEOLOGICAL SURVEY IS CONDUCTING MERCURY CYCLING STUDIES IN THE FLORIDA EVERGLADES.

U.S. Department of the Interior U.S. Geological Survey Fact Sheet FS-216-95 